\title{
Adherence to the preventive strategies for nonsteroidal anti-inflammatory drug- or low-dose aspirin-induced gastrointestinal injuries
}

\author{
Tsuyoshi Fujita $\cdot$ Hiromu Kutsumi $\cdot$ \\ Tsuyoshi Sanuki • Takanobu Hayakumo • \\ Takeshi Azuma
}

Received: 29 January 2013/Accepted: 30 January 2013/Published online: 5 March 2013

(C) The Author(s) 2013. This article is published with open access at Springerlink.com

\begin{abstract}
As the aging of the population advances, the use of nonsteroidal anti-inflammatory drugs (NSAIDs) and/ or low-dose aspirin (LDA) is increasing. Their use is accompanied by a risk of serious complications, such as hemorrhage or perforation of the gastrointestinal tract. Therefore, gastroprotective strategies upon the prescription of NSAIDs/LDA are outlined in several guidelines or recommendations. Because all NSAIDs including cyclooxygenase (COX)-2 inhibitors have cardiovascular (CV) toxicity, recent guidelines are based on not only GI risks but also CV risks of NSAID users. Assessment of the adherence to evidence-based guidelines or recommendations for the safe prescription of NSAIDs/LDA in clinical practice is an important issue. Here, we summarize randomized controlled trials (RCTs) on the preventive effects of antisecretory drugs for NSAID- or LDA-induced peptic ulcers. Then, we describe preventive strategies upon the prescription of NSAIDs/LDA outlined in several guidelines or recommendations, and describe studies on adherence and outcomes of adherence to these preventive strategies. Finally, we discuss strategies to increase the adherence rate, and changing pattern of GI events associated with NSAIDs/LDA. In Japan, the preventive strategies upon the prescription of NSAIDs/LDA are expected to spread rapidly because the use of proton pump inhibitors for the prevention of recurrence of NSAID- or LDA-induced
\end{abstract}

T. Fujita · H. Kutsumi - T. Hayakumo - T. Azuma $(\bowtie)$ Department of Gastroenterology, Kobe University Graduate School of Medicine, 7-5-1 Kusunoki-cho, Chuo-ku, Kobe 650-0017, Japan

e-mail: azumat@med.kobe-u.ac.jp

T. Sanuki

Department of Gastroenterology, Miki City Hospital, 58-1 Kasa, Miki 673-0402, Japan peptic ulcers and the use of COX-2 for the palliation of acute pain were recently approved under the national health insurance system. Further studies on adherence to the preventive strategies and the outcomes of adherence, which include both GI events and CV events, in the Japanese population are required.

Keywords Adherence - Preventive strategy ·

Nonsteroidal anti-inflammatory drug · Low-dose aspirin . Gastrointestinal injury

\section{Introduction}

Nonsteroidal anti-inflammatory drugs (NSAIDs) are one of the medicines most frequently prescribed in regular practice, and are used for the suppression of fever, pain, and inflammation in various acute and chronic diseases, such as headache, musculoskeletal pain, osteoarthritis, and rheumatoid arthritis. Low-dose aspirin (LDA), which is another of the most frequently prescribed medicines, is used for secondary prevention of ischemic heart disease and cerebrovascular disease. As the aging of the population advances, the number of patients with chronic pain, cardiovascular disease, or cerebrovascular disease is increasing, as is the number of prescriptions of NSAIDs and/or LDA.

However, it is well known that NSAIDs and LDA cause gastrointestinal mucosal injuries, and the prescriptions of NSAIDs and LDA are accompanied by the risk of serious complications, such as hemorrhage or perforation of the gastrointestinal tract. NSAID/LDA-induced gastrointestinal injuries are not often associated with gastrointestinal symptoms, whereas gastrointestinal symptoms often develop without mucosal injury in NSAID/LDA users. The 
first sign of NSAID/LDA-induced gastrointestinal injuries in asymptomatic individuals may be a life-threatening complication [1]. In addition, it is reported that NSAIDand LDA-induced hemorrhagic ulcers often require additional endoscopic hemostasis treatment, and their treatment is more difficult [2].

Upon the prescription of NSAIDs, gastroprotective strategies are outlined in several guidelines considering gastrointestinal (GI) risk factors that were identified in observational studies. Because it was found that NSAIDs including cyclooxygenase (COX)-2 inhibitors have cardiovascular (CV) toxicity, recent guidelines were developed on the basis of not only GI risks but also CV risks of NSAID users [3-6].

In Japan, guidelines for gastric ulcers were published in 2003, and were revised in 2007 [7]. In addition, peptic ulcer practice guidelines were published by the Japanese Society of Gastroenterology in 2009 [8]. In these guidelines, NSAID users with advanced age and/or peptic ulcer history were considered as high-GI-risk patients, and proton pump inhibitor (PPI) or prostaglandin analogue (PA) therapy is recommended for them for the prevention of NSAID-induced GI injury. In Japan, however, until the use of lansoprazole at $15 \mathrm{mg}$ was approved for the prevention of recurrence of NSAID- or LDA-induced peptic ulcers in July 2010, the practice outlined in the guidelines could not be provided under the national health insurance system. In addition, PA or high-dose histamine type 2-receptor antagonist $\left(\mathrm{H}_{2} \mathrm{RA}\right)$ therapy is not presently approved for the prevention of NSAID-induced peptic ulcers under the health insurance system in Japan.

The use of COX-2 inhibitors, which can decrease GI toxicity associated with nonselective COX inhibition, is a different strategy from the use of gastroprotective agents for high-GI-risk NSAID users. In Japan, however, the use of celecoxib under the health insurance system had been limited until the indication of celecoxib use was approved in the palliation of acute pain in December 2011.

Recently, reports based on studies of the adherence to preventive strategies for NSAID- or LDA-induced gastrointestinal injury have been accumulating [9-20]. In this review, we focus on the adherence to the preventive strategies for NSAID/LDA-induced gastrointestinal injuries, and the outcome of such adherence.

\section{Preventive effects of PPIs for NSAID-induced peptic ulcers in at-risk patients}

A summary of randomized controlled trials (RCTs) on the preventive effects of PPIs for NSAID-induced peptic ulcers in at-risk patients is shown in Table 1. Two studies conducted on patients with a history of peptic ulcers were reported in Japan in 2012. Both low-dose lansoprazole [21] and esomeprazole [22] were more effective than gefarnate or placebo in reducing the risk of peptic ulcer recurrence, and hazard ratios (HRs) of 0.2510 (95\% confidence interval (CI) 0.1400-0.4499) and 0.09 (95\% CI 0.04-0.20) were reported, respectively.

In a trial of esomeprazole that was conducted outside of Japan, the estimated cumulative proportions of patients developing peptic ulcer at 6 months were reported as $17.0 \%$ (95\% CI 13.2-20.8) with placebo, $5.2 \%$ (95\% CI 3.0-7.4) with esomeprazole at $20 \mathrm{mg}$, and $4.6 \%$ (95\% CI 2.6-6.6) with esomeprazole at $40 \mathrm{mg}$ in at-risk patients using NSAIDs [23].

Chan et al. [24] reported that omeprazole was superior to the eradication of Helicobacter pylori in preventing recurrent upper GI bleeding in a 6-month treatment period in patients who were taking naproxen (omeprazole $4.4 \%$ vs. placebo $24.4 \%, p=0.005$ ). In addition, the efficacy of lansoprazole in the prevention of peptic ulcer relapse after eradication of Helicobacter pylori in naproxen users was reported by Lai et al. At 8 weeks, significantly fewer patients in the lansoprazole group (4.5\%) than in the group with Helicobacter pylori eradication alone (42.9\%) developed recurrence of ulcers [25].

Graham et al. conducted a study that compared PPI with misoprostol in NSAID users without Helicobacter pylori infection who had a history of gastric ulcer. The estimated cumulative proportion of patients developing peptic ulcer at 3 months was reported to be $53 \%$ in the placebo group, $21 \%$ in the group with lansoprazole at $15 \mathrm{mg}, 17 \%$ in the group with lansoprazole at $30 \mathrm{mg}$, and $8 \%$ in the group with misoprostol, indicating that lansoprazole is effective for the prevention of NSAID-induced peptic ulcers, but is not superior to misoprostol. However, poor compliance due to adverse events such as diarrhea was reported in the misoprostol group [26].

There have been three studies that compared COX-2 inhibitor with PPI plus nonselective NSAIDs in a high-GIrisk group with a history of bleeding peptic ulcer [27-29]. Chan et al. [27] reported that, in a 6-month treatment period, the proportions of patients who developed upper GI bleeding were $6.4 \%$ in the omeprazole plus diclofenac group and $4.9 \%$ in the celecoxib group $(p=0.60)$. Lai et al. [28] reported similar results using lansoprazole in a 6-month treatment period (lansoprazole plus naproxen $6.3 \%$ vs. celecoxib $3.7 \%, p=0.37$ ). Chan et al. [29] also reported that the proportions of patients who developed peptic ulcers confirmed by endoscopy at 6 months were $32.3 \%$ in the omeprazole plus diclofenac group and $24.1 \%$ in the celecoxib group $(p=0.15)$. These studies indicate that COX-2 inhibitor is as effective as PPI co-therapy.

A trial that compared the effect of PPI plus COX-2 inhibitor with that of COX-2 inhibitor was reported in 2007 


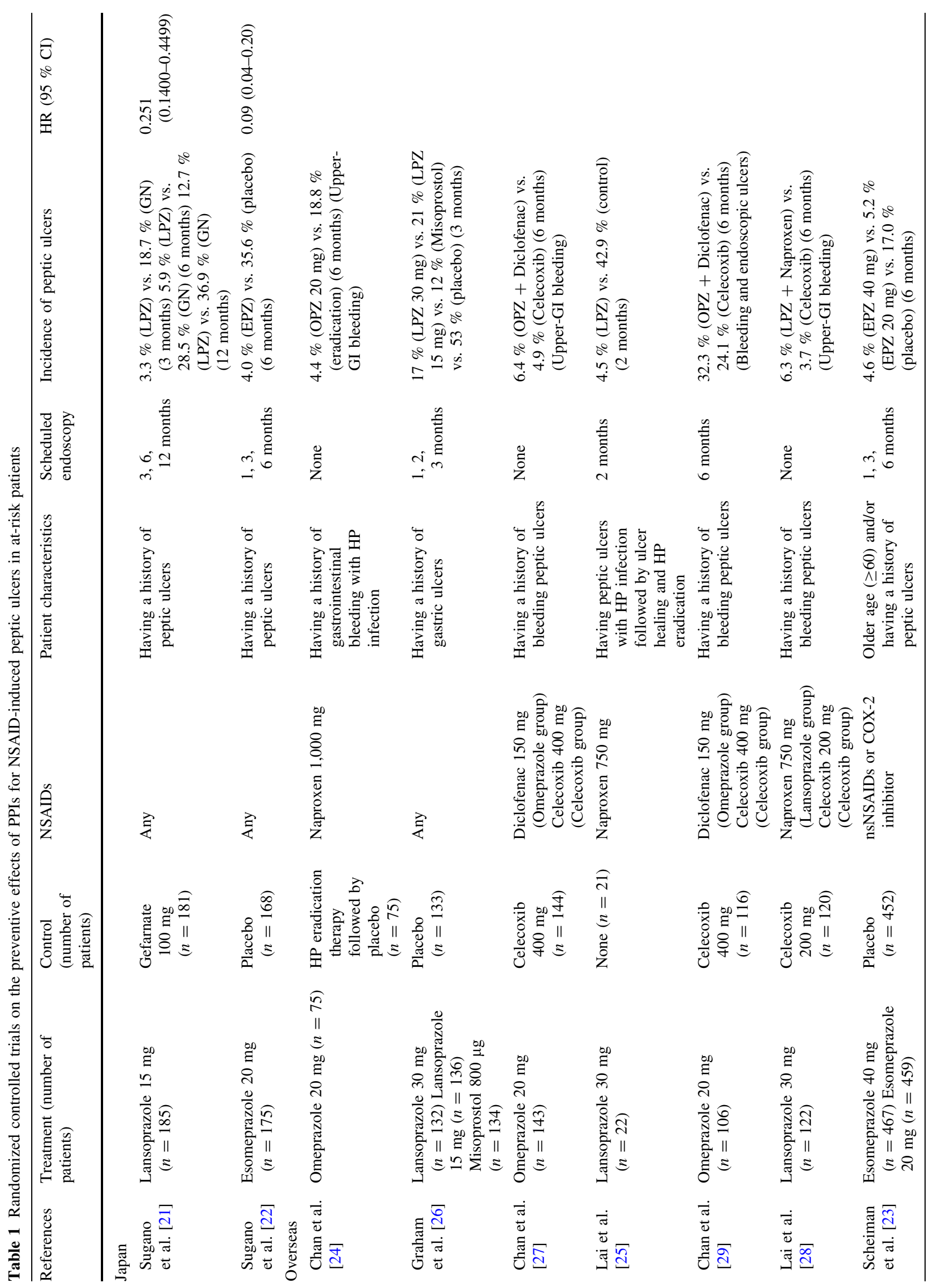




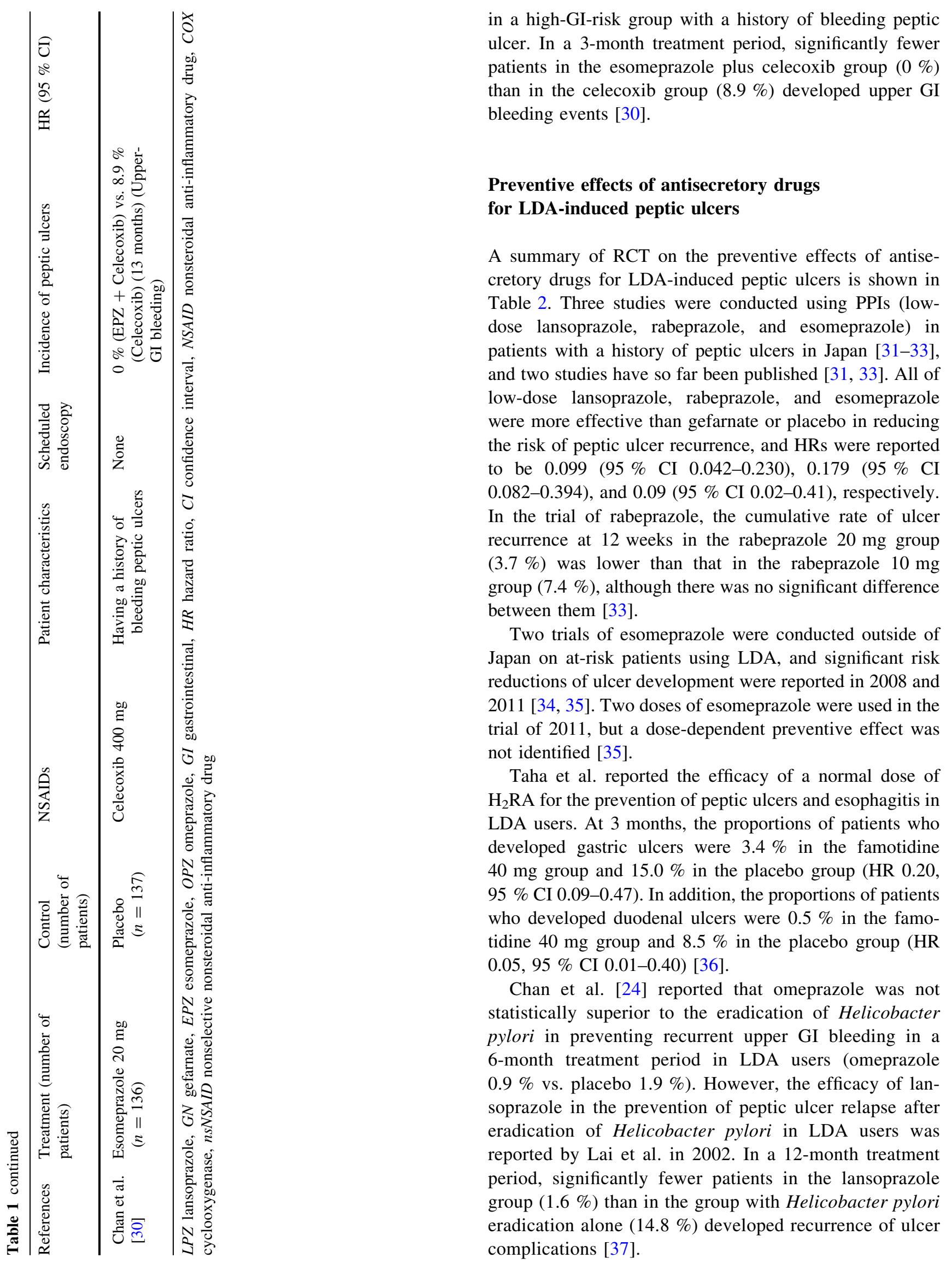


Table 2 Randomized controlled trials on the preventive effects of antisecretory drugs for LDA-induced peptic ulcers

\begin{tabular}{|c|c|c|c|c|c|c|}
\hline References & $\begin{array}{l}\text { Treatment } \\
\text { (number of } \\
\text { patients) }\end{array}$ & $\begin{array}{l}\text { Control } \\
\text { (number of } \\
\text { patients) }\end{array}$ & Patient characteristics & $\begin{array}{l}\text { Scheduled } \\
\text { endoscopy }\end{array}$ & $\begin{array}{l}\text { Incidence of peptic } \\
\text { ulcers }\end{array}$ & HR $(95 \%$ CI $)$ \\
\hline \multicolumn{7}{|l|}{ Japan } \\
\hline $\begin{array}{l}\text { Sugano et al. } \\
\text { [31] }\end{array}$ & $\begin{array}{l}\text { Lansoprazole } \\
\qquad \begin{array}{l}15 \mathrm{mg} \\
(n=226)\end{array}\end{array}$ & $\begin{array}{l}\text { Gefarnate } \\
100 \mathrm{mg} \\
(n=235)\end{array}$ & $\begin{array}{l}\text { Having a history of } \\
\text { peptic ulcers }\end{array}$ & $\begin{array}{l}3,6 \\
12 \text { months }\end{array}$ & $\begin{array}{l}1.5 \% \text { (LPZ) vs. } 15.2 \% \\
\text { (GN) (3 months) } \\
2.1 \% \text { (LPZ) vs. } \\
24.0 \%(\mathrm{GN}) \\
\text { (6 months) } 3.7 \% \\
\text { (LPZ) vs. } 31.7 \% \\
\text { (GN) (12 months) }\end{array}$ & $\begin{array}{l}0.099 \\
\quad(0.042-0.230)\end{array}$ \\
\hline $\begin{array}{l}\text { AstraZeneca }{ }^{a} \\
{[32]}\end{array}$ & $\begin{array}{l}\text { Esomeprazole } \\
20 \mathrm{mg} \\
(n=182)\end{array}$ & $\begin{array}{l}\text { Placebo } \\
\qquad(n=182)\end{array}$ & $\begin{array}{l}\text { Having a history of } \\
\text { peptic ulcers }\end{array}$ & $\begin{array}{l}3,6,9,12 \\
15, \\
18 \text { months }\end{array}$ & $\begin{array}{r}1.7 \% \text { (EPZ) vs. } 18.8 \% \\
\text { (placebo) (12 months) }\end{array}$ & $0.09(0.02-0.41)$ \\
\hline $\begin{array}{l}\text { Sanuki et al. } \\
\text { [33] }\end{array}$ & $\begin{array}{l}\text { Rabeprazole } \\
20 \mathrm{mg}(n=89) \\
\text { Rabeprazole } \\
10 \mathrm{mg}(n=87)\end{array}$ & $\begin{array}{l}\text { Gefarnate } \\
100 \mathrm{mg} \\
(n=85)\end{array}$ & $\begin{array}{l}\text { Having a history of } \\
\text { peptic ulcers }\end{array}$ & 3 months & $\begin{array}{l}5.5 \% \text { (RPZ) vs. } 26.7 \% \\
\text { (GN) (3 months) } \\
3.7 \% \text { (RPZ } 20 \mathrm{mg}) \\
7.4 \% \text { (RPZ } 10 \mathrm{mg})\end{array}$ & $\begin{array}{l}0.179 \\
\quad(0.082-0.394)\end{array}$ \\
\hline \multicolumn{7}{|l|}{ Overseas } \\
\hline $\begin{array}{l}\text { Chan et al. } \\
{[24]}\end{array}$ & $\begin{array}{l}\text { Omeprazole } \\
20 \mathrm{mg} \\
(n=125)\end{array}$ & $\begin{array}{l}\text { HP eradication } \\
\text { therapy } \\
\text { followed by } \\
\text { placebo } \\
(n=125)\end{array}$ & $\begin{array}{l}\text { Having a history of } \\
\text { gastrointestinal } \\
\text { bleeding with HP } \\
\text { infection }\end{array}$ & None & $\begin{array}{l}0.9 \% \text { (OPZ } 20 \mathrm{mg} \text { ) vs. } \\
1.9 \% \text { (eradication) } \\
\text { (6 months) (Upper-GI } \\
\text { bleeding) } \\
\text { Statistically not } \\
\text { significant }\end{array}$ & \\
\hline Lai et al. [37] & $\begin{array}{l}\text { Lansoprazole } \\
\qquad 30 \mathrm{mg}(n=62)\end{array}$ & $\begin{array}{l}\text { Placebo } \\
\qquad(n=61)\end{array}$ & $\begin{array}{l}\text { Having ulcer } \\
\text { complications with HP } \\
\text { infection followed by } \\
\text { ulcer healing and HP } \\
\text { eradication }\end{array}$ & None & $\begin{array}{l}1.6 \% \text { (LPZ } 30 \mathrm{mg} \text { ) vs. } \\
14.8 \% \text { (placebo) } \\
\text { (12 months) (ulcer } \\
\text { complications: } \\
\text { bleeding, perforation, } \\
\text { or obstruction) }\end{array}$ & \\
\hline $\begin{array}{l}\text { Yeomans } \\
\text { et al. [34] }\end{array}$ & $\begin{array}{l}\text { Esomeprazole } \\
20 \mathrm{mg} \\
(n=493)\end{array}$ & $\begin{array}{l}\text { Placebo } \\
\qquad(n=498)\end{array}$ & Older age $(\geq 60)$ & $\begin{array}{l}2, \\
6.5 \text { months }\end{array}$ & $\begin{array}{l}1.8 \% \text { (EPZ) vs. } 6.2 \% \\
\text { (control) }(6.5 \text { months) }\end{array}$ & \\
\hline $\begin{array}{l}\text { Taha et al. } \\
{[36]}\end{array}$ & $\begin{array}{l}\text { Famotidine } \\
\qquad 40 \mathrm{mg} \\
\quad(n=204)\end{array}$ & $\begin{array}{l}\text { Placebo } \\
\qquad(n=200)\end{array}$ & Aged $\geq 18$ & 3 months & $\begin{array}{l}3.4 \% \text { (Famotidine) vs. } \\
15.0 \% \text { (placebo) } \\
\text { (GU, } 3 \text { months) } 0.5 \% \\
\text { (Famotidine) vs. } \\
8.5 \% \text { (placebo) (DU, } \\
3 \text { months) }\end{array}$ & $\begin{array}{l}0.20(0.09-0.47) \\
(\mathrm{GU}) 0.05 \\
(0.01-0.40) \\
(\mathrm{DU})\end{array}$ \\
\hline $\mathrm{Ng}$ et al. [38] & $\begin{array}{l}\text { Pantoprazole } \\
20 \mathrm{mg}(n=65)\end{array}$ & $\begin{array}{l}\text { Famotidine } \\
\quad 80 \mathrm{mg} \\
(n=65)\end{array}$ & $\begin{array}{l}\text { Having a history of } \\
\text { upper gastrointestinal } \\
\text { bleeding or dyspepsia } \\
\text { due to peptic ulcers/ } \\
\text { erosion }\end{array}$ & None & $\begin{array}{l}0 \% \text { (PPZ) vs. } 20.0 \% \\
\text { (FAM) (12 months) } \\
\text { (Dyspeptic or bleeding } \\
\text { ulcers/erosion) }\end{array}$ & \\
\hline $\begin{array}{l}\text { Bhatt et al. } \\
\text { [40] }\end{array}$ & $\begin{array}{l}\text { Omeprazole } \\
20 \mathrm{mg} \\
(n=1,876)\end{array}$ & $\begin{array}{l}\text { Placebo } \\
\qquad(n=1,885)\end{array}$ & $\begin{array}{l}\text { Having acute coronary } \\
\text { syndrome or } \\
\text { percutaneous coronary } \\
\text { intervention receiving } \\
\text { aspirin and } \\
\text { clopidogrel }\end{array}$ & None & $\begin{array}{l}1.1 \% \text { (OPZ) vs. } 2.9 \% \\
\text { (placebo) (6 months) } \\
\text { (GI events: overt or } \\
\text { occult bleeding, } \\
\text { symptomatic } \\
\text { gastroduodenal ulcers } \\
\text { or erosion, } \\
\text { obstruction, or } \\
\text { perforation) }\end{array}$ & $0.34(0.18-0.63)$ \\
\hline $\begin{array}{l}\text { Scheiman } \\
\text { et al. [35] }\end{array}$ & $\begin{array}{l}\text { Esomeprazole } \\
\quad 40 \mathrm{mg} \\
(n=817) \\
\text { Esomeprazole } \\
20 \mathrm{mg} \\
(n=804)\end{array}$ & $\begin{array}{l}\text { Placebo } \\
\qquad(n=805)\end{array}$ & $\begin{array}{l}\text { Older age }(\geq 65) \text {, older } \\
\text { age }(\geq 60) \text { with one or } \\
\text { more risk factors, aged } \\
\geq 18 \text { with a history of } \\
\text { peptic ulcers }\end{array}$ & 2 , 6.5 months & $\begin{array}{l}1.5 \% \text { (EPZ } 40 \mathrm{mg}) \text { vs. } \\
1.1 \% \text { (EPZ } 20 \mathrm{mg}) \\
\text { vs. } 7.4 \% \text { (control) } \\
(6.5 \text { months) }\end{array}$ & $\begin{array}{l}0.19(0.10-0.37) \\
(\text { EPZ } 40 \mathrm{mg}) \\
0.14 \\
(0.07-0.30) \\
(\text { EPZ } 20 \mathrm{mg})\end{array}$ \\
\hline
\end{tabular}


Table 2 continued

\begin{tabular}{|c|c|c|c|c|c|c|}
\hline References & $\begin{array}{l}\text { Treatment } \\
\text { (number of } \\
\text { patients) }\end{array}$ & $\begin{array}{l}\text { Control } \\
\text { (number of } \\
\text { patients) }\end{array}$ & Patient characteristics & $\begin{array}{l}\text { Scheduled } \\
\text { endoscopy }\end{array}$ & $\begin{array}{l}\text { Incidence of peptic } \\
\text { ulcers }\end{array}$ & HR $(95 \%$ CI $)$ \\
\hline $\mathrm{Ng}$ et al. [39] & $\begin{array}{l}\text { Esomeprazole } \\
\quad 20 \mathrm{mg} \\
(n=163)\end{array}$ & $\begin{array}{l}\text { Famotidine } \\
\quad 40 \mathrm{mg} \\
(n=148)\end{array}$ & $\begin{array}{l}\text { Having acute coronary } \\
\text { syndrome or ST } \\
\text { elevation myocardial } \\
\text { infarction receiving } \\
\text { aspirin, clopidogrel, } \\
\text { and enoxaparin or } \\
\text { thrombolytics }\end{array}$ & None & $\begin{array}{l}0.6 \%(\mathrm{EPZ} \\
19.2 \text { weeks) vs. } 6.1 \% \\
\text { (FAM, } 17.6 \text { weeks) }\end{array}$ & $\begin{array}{l}0.095 \\
\quad(0.005-0.504)\end{array}$ \\
\hline
\end{tabular}

$L P Z$ lansoprazole, $G N$ gefarnate, $E P Z$ esomeprazole, $R P Z$ rabeprazole, $O P Z$ omeprazole, $P P Z$ pantoprazole, $F A M$ famotidine, $G U$ gastric ulcer, $D U$ duodenal ulcer, $G I$ gastrointestinal, $H R$ hazard ratio, $C I$ confidence interval, $L D A$ low-dose aspirin

${ }^{a}$ Not only the Japanese patients but also the foreign patients were included in this study

$\mathrm{Ng}$ et al. $[38,39]$ reported two trials that compared the effect of PPI with that of $\mathrm{H}_{2} \mathrm{RA}$ for the prevention of upper GI complications in LDA users. In a trial reported in 2010, the effect of pantoprazole at $20 \mathrm{mg}$ was compared with that of high-dose famotidine $(80 \mathrm{mg})$ in LDA users with a history of upper GI bleeding or dyspepsia due to peptic ulcer/erosion. In a 12-month treatment period, significantly fewer patients in the pantoprazole group (0\%) than in the famotidine group $(20 \%)$ developed dyspeptic or bleeding ulcer/erosion [38]. Furthermore, in another trial reported in 2012, the effect of esomeprazole at $20 \mathrm{mg}$ was compared with that of famotidine at $40 \mathrm{mg}$ in patients with acute coronary syndrome or ST elevation myocardial infarction receiving a combination of aspirin, clopidogrel, and either enoxaparin or thrombolytics. In a mean follow-up period of approximately 5 months, $0.6 \%$ of patients in the esomeprazole group and $6.1 \%$ of patients in the famotidine group developed upper GI bleeding, perforation, or obstruction from ulcer/erosion (HR 0.095, $95 \%$ CI 0.005-0.504) [39].

Bhatt et al. also reported the preventive effect of PPI for GI events in patients receiving dual antiplatelet therapy (aspirin plus clopidogrel). At 6 months, the gastrointestinal event rates were $1.1 \%$ with omeprazole and $2.9 \%$ with placebo (HR 0.34, $95 \%$ CI 0.18-0.63) [40].

\section{Definitions of high-risk NSAID users and recommended preventive strategies in recent guidelines}

The definitions of GI risk and CV risk and recommended preventive strategies in recent guidelines on NSAID therapy are shown in Table 3. A history of peptic ulcer complication, a history of peptic ulcer disease, advanced age, concomitant use of anticoagulants, concomitant use of aspirin, concomitant use of corticosteroid, and highdose NSAIDs are consistently considered as definite GI risk factors in the guidelines. Helicobacter pylori infection, concomitant use of selective serotonin reuptake inhibitors, and concomitant use of bisphosphonate are also identified as GI risk factors in some observational studies [4, 5]. Lanza et al. [5] recently reported guidelines that stratified the GI risk into low- (no risk factors), moderate- (1-2 risk factors), and high-risk groups [multiple ( $\geq 3$ ) risk factors, or a history of peptic ulcer complications, or concomitant use of corticosteroids or anticoagulants] by the type and number of risk factors. The use of COX-2 plus PPI/misoprostol is consistently recommended for high-GI-risk patients in guidelines, although misoprostol is not recommended, owing to the occurrence of GI side effects [43], in several guidelines $[4,6]$.

High CV risk is defined as the requirement for LDA for prevention of serious $\mathrm{CV}$ events. In several guidelines, an estimated 10-year risk of a fatal CV event of more than $10 \%$ or more than $20 \%$ in patients without established $\mathrm{CV}$ disease is considered as a high $\mathrm{CV}$ risk $[3,6]$.

Both COX-2 inhibitors and nonselective NSAIDs share similar CV risks, with an increase in acute myocardial infarction, congestive heart failure, and sudden death [1]. In a recent review on the cardiovascular risk associated with NSAIDs, however, it was suggested that naproxen and low-dose ibuprofen are least likely to increase cardiovascular risk [41]. Therefore, the use of naproxen as an NSAID is consistently recommended for high-CV-risk patients in guidelines.

\section{Adherence to evidence-based guidelines for the safe prescription of NSAIDs}

Assessment of the adherence to evidence-based guidelines for the safe prescription of NSAIDs in clinical practice is an important issue. A summary of several studies on 


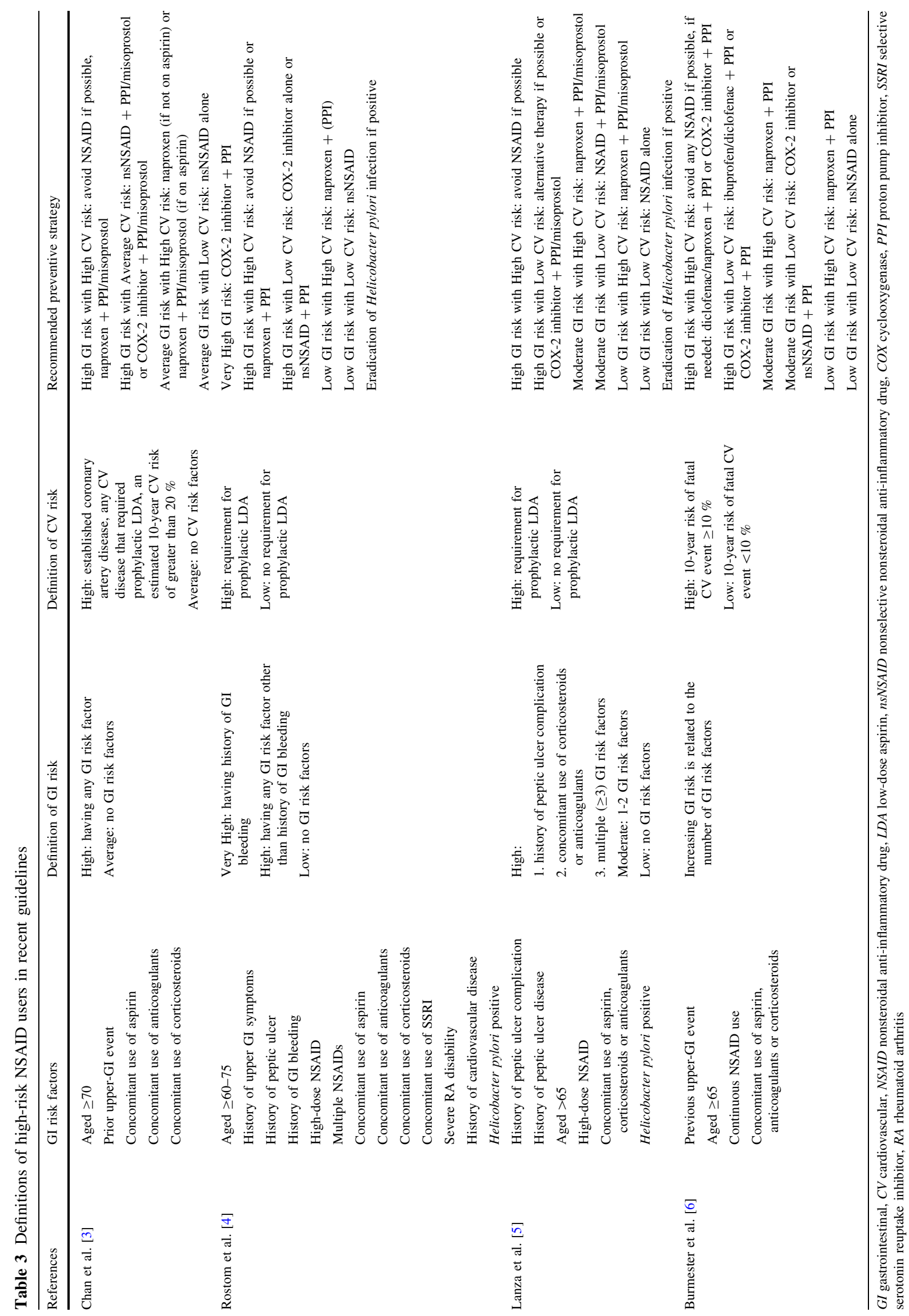


adherence to preventive strategies for NSAID-induced gastrointestinal injury is shown in Table 4.

In two retrospective cross-sectional studies in the USA, which were conducted on 76,765 NSAID users from the database of the Tennessee Medicaid program and 707,244 NSAID users from the database of Veterans Affairs, it was shown that the rate of adherence to preventive strategies for NSAID-induced gastrointestinal injury was low $[9,10]$. Smalley et al. [9] reported that the proportions of patients who received gastroprotective therapy recommended in the guidelines were $18 \%$ in the NSAID users with a single GI risk factor and $30 \%$ in the NSAID users with two or more GI risk factors. Abraham et al. reported that the rates of adherence to preventive strategies were $27.2 \%$ in the NSAID users with at least 1 GI risk factor, $39.7 \%$ in those with at least 2 GI risk factors, and $41.8 \%$ in those with at least 3 GI risk factors. In addition, it was reported that NSAID prescription $\geq 90$ days was a predictor of nonadherence [10].

In the Netherlands, a similar retrospective study on 50,126 NSAID users from the Integrated Primary Care Information database was carried out. In that study, although $43.3 \%$ of NSAID users had GI-associated risk, the rate of adherence to preventive strategies was reported to be $21.9 \%$ in high-risk NSAID users. This rate rose from $6.9 \%$ in 1996 to $39.4 \%$ in 2006 in high-risk NSAID users, but was still at a low level [11].

Recently, a prospective cross-sectional observational study that evaluated both GI risk and CV history in 17,105 osteoarthritis (OA) patients who visited 1,760 doctors throughout the Spanish National Health System in a single day was conducted [12]. Among these OA patients, $93.4 \%$ had more than one GI risk factor, $60.3 \%$ were in the highGI-risk group, and $32 \%$ had a CV history. Approximately four-fifths of patients received NSAID therapy. Although $25.3 \%$ had both high GI risk and CV history, $74.4 \%$ of this subpopulation received nonselective NSAIDs (94.5\% of them also received gastroprotective agents) or COX-2 inhibitors $(82.4 \%$ of them also received gastroprotective agents), which are prescriptions that should be avoided according to the guidelines. In addition, $61.8 \%$ of patients with high GI risk and no CV history were treated with COX-2 inhibitors alone or nonselective NSAIDs plus PPI, although the use of COX-2 inhibitors plus PPI is recommended for those patients in the guidelines. These data suggest that assessments of CV risk and stratified GI risk are not fully implemented in routine clinical practice, and show the difficulty in translating guidelines into clinical practice [12].

On the other hand, over-prescription of PPI and/or COX-2 inhibitors in patients with no risk factors was indicated in studies in both the Netherlands and Spain [11, 12].

\section{Outcomes of adherence to preventive strategies for the safe prescription of NSAIDs}

A summary of several recent studies on the outcomes of adherence to preventive strategies for NSAID-induced GI injury is shown in Table 5. Goldstein et al. conducted a retrospective cross-sectional study using a managed-care database in the USA. Of 2,634 NSAID users (nonselective NSAIDs 1,312, COX-2 inhibitors 1,322) receiving concomitant PPI or $\mathrm{H}_{2} \mathrm{RA}$ therapy, 463 NSAIDs users (nonselective NSAIDs 161, COX-2 inhibitors 302) developed upper-GI events (peptic ulcer and/or bleeding). Of NSAID users receiving concomitant PPI therapy, $68 \%$ had a PPI coverage rate of $80 \%$ or more over the course of NSAID treatment. A significantly higher risk of upper-GI events was observed in nonselective NSAID users with a PPI coverage rate of less than $80 \%$ than in those with a PPI coverage rate of $80 \%$ or more (OR 2.4, $95 \%$ CI 1.0-5.6), but no such relationship was observed in COX-2 inhibitor users [13].

Abraham et al. conducted a retrospective cohort study to examine the effect of PPI gastroprotection on the risk of NSAID-related upper-GI events in 481,980 NSAID users in the Veterans Affairs database. In that cohort, PPIs were co-prescribed for $19.8 \%$, and 2,753 upper-GI events occurred in 220,662 person-years of follow-up. HR (95\% CI) of upper-GI events on traditional NSAIDs alone, coxib alone, traditional NSAIDs plus PPI, and coxib plus PPI were estimated to be 1.8 (1.6-2.0), 1.8 (1.5-2.0), 1.1 (0.7-4.6), and 1.1 (0.6-5.2), respectively. In addition, an inverse relationship between PPI coverage rate and HR of upper-GI events was reported [15]. Moreover, Abraham et al. reported a retrospective cohort study of 3,566 NSAID users who had suffered an NSAID-related upper-GI event by using the Veterans Affairs database. Hospitalization occurred in $47.5 \%$ of that cohort, and PPI therapy was associated with a $30 \%$ reduction in hospitalization compared with that in those with no PPI. As a result, although it was associated with higher pharmacy costs, a substantial reduction of five-year medical costs was observed with PPI therapy [17].

Van Soest et al. conducted a nested case-control study by using the Integrated Primary Care Information database in the Netherlands, and reported a strong inverse relationship between the gastroprotective agent coverage rate over the course of NSAID treatment and the risk of upper-GI complications (symptomatic upper-GI ulcer and/or upperGI bleeding/perforation) in high-GI-risk NSAID users. Compared with NSAID users with a gastroprotective agent coverage rate of $\geq 80 \%$, NSAID users with gastroprotective agent coverage rates of $20-80 \%$ and of $<20 \%$ had 2.5 -fold and 4.0-fold increased risks of upper-GI complications, respectively [14]. Moreover, van Soest et al. [18] 


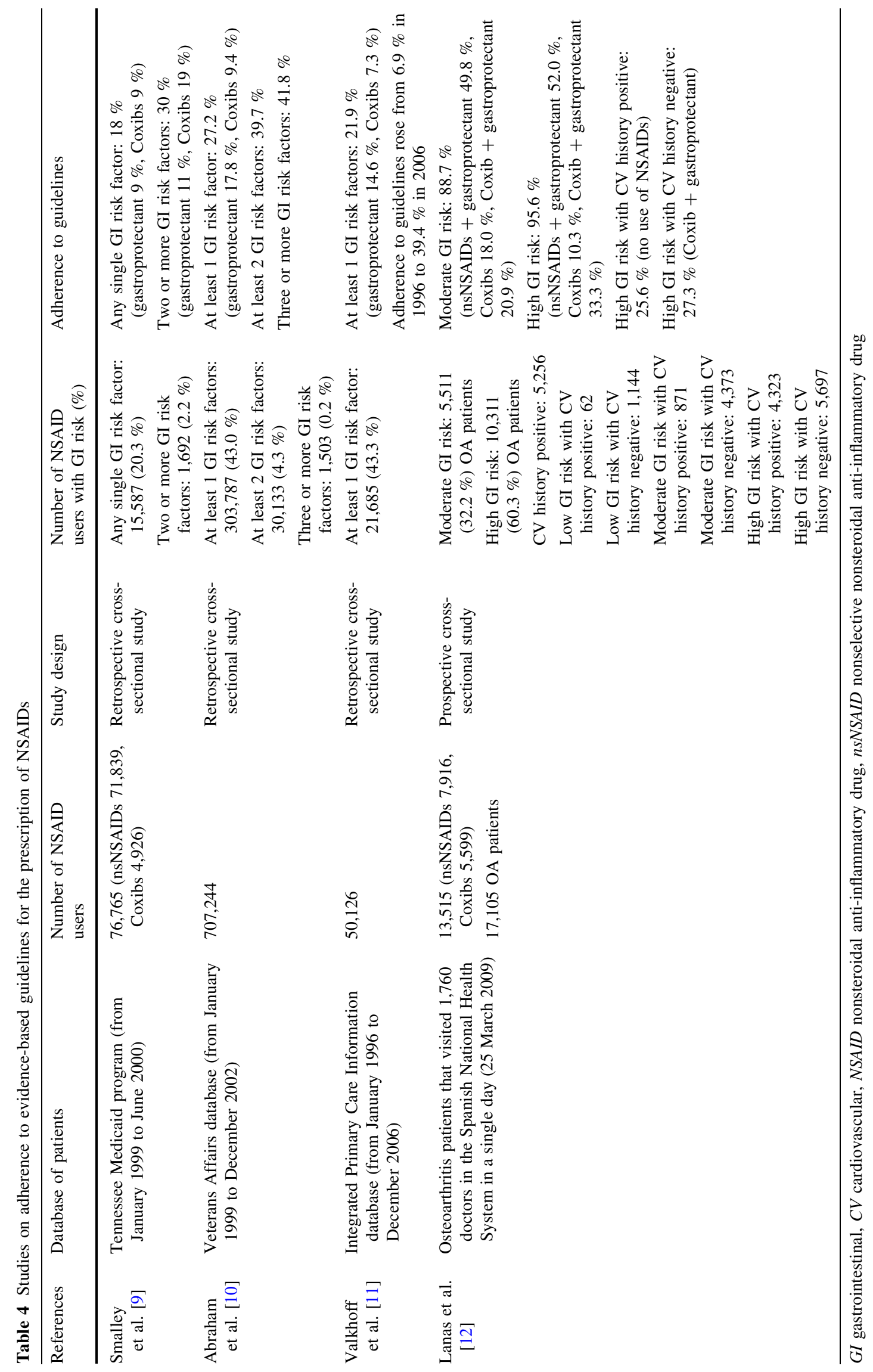




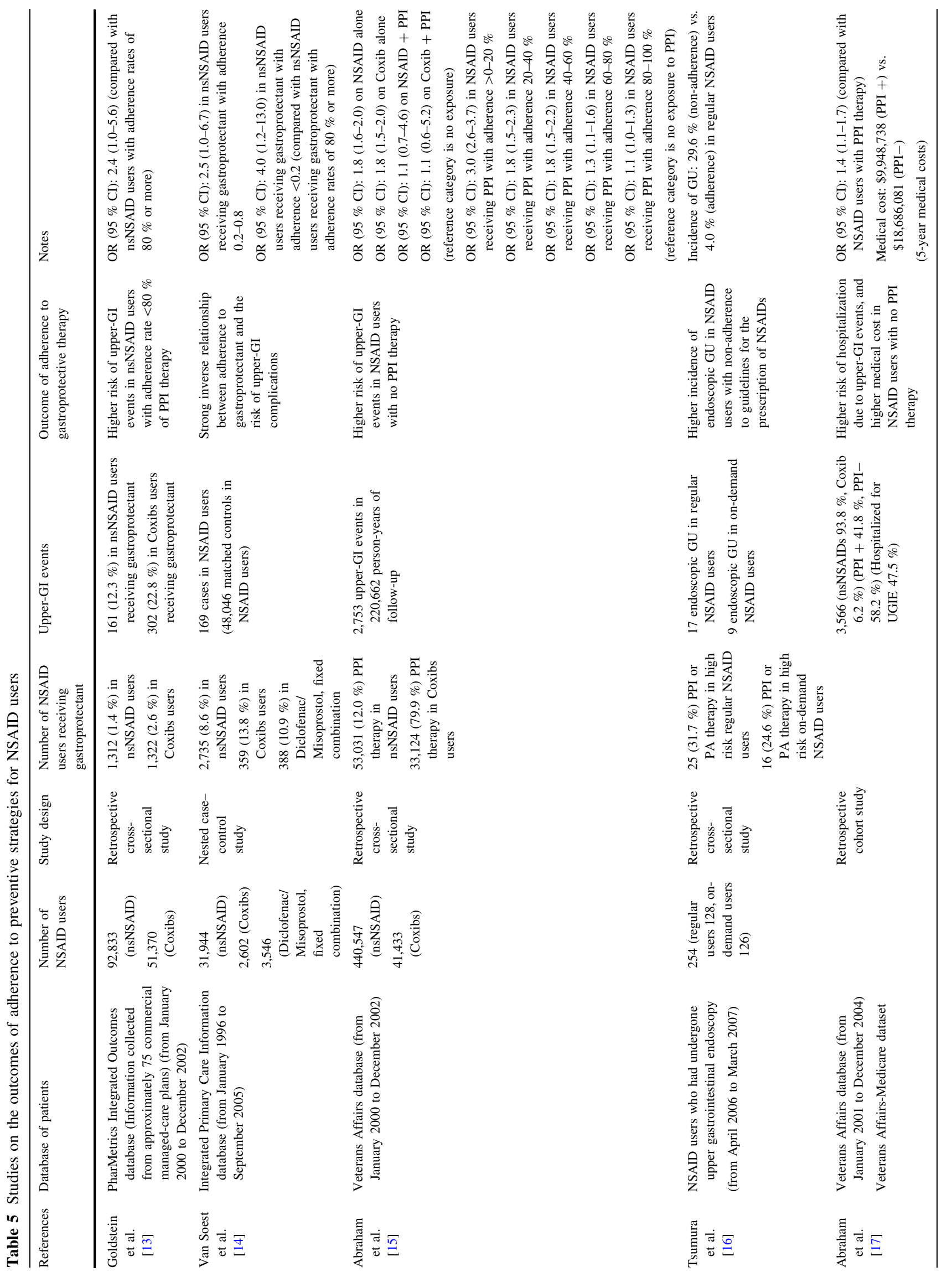


conducted a similar nested case-control study by using three European databases (from the UK, the Netherlands, and Italy), and a similar relationship between gastroprotective agent coverage rate over the course of NSAID treatment and the risk of upper-GI events was identified.

To date, no large-scale observational studies on the outcomes of adherence to preventive strategies for NSAIDinduced GI injury have been reported in Japan. In a retrospective study by Tsumura et al. [16], however, the association between adherence to guidelines for safe prescription of NSAIDs and the incidence of gastric mucosal lesions in NSAID users who had undergone endoscopy was examined, and it was reported that gastric ulcers were more frequently observed in the non-adherence group than in the adherence group (29.6 vs. $4.0 \%$ ).

\section{Recommended preventive strategies in at-risk LDA users}

The use of LDA for cardioprophylaxis is associated with a 2- to 4-fold increase in the risk of an upper-GI event [42]. As for LDA-induced GI injury, similar factors identified for NSAID-induced GI injury have been suggested as GI risk factors in LDA users [43], although there have been far fewer studies on the risk of LDA therapy. In the ACCF/ ACG/AHA 2008 expert consensus document, a history of peptic ulcer complication, a history of peptic ulcer disease, GI bleeding, dual antiplatelet therapy, concomitant use of anticoagulant, concomitant use of corticosteroid, age $\geq 60$, and dyspepsia/gastroesophageal reflux disease (GERD) symptoms were considered as risk factors in LDA users, and PPI therapy was recommended for the prevention of LDA-induced GI injury in at-risk LDA users [42]. Before starting chronic LDA therapy, testing for and eradicating Helicobacter pylori in patients with a history of ulcer disease is also recommended [42].

\section{Outcomes of recommended preventive strategies in at-risk LDA users}

Regarding the outcomes of preventive strategies in at-risk LDA users, only a few studies have so far been carried out. $\mathrm{Ng}$ et al. conducted a retrospective cohort study on the effect of treatment with antisecretory agents for uppergastrointestinal bleeding in 987 patients with LDA and clopidogrel co-therapy. The risk of upper-GI bleeding was reported to be marginally reduced by $\mathrm{H}_{2} \mathrm{RA}$ (OR 0.43 , $95 \%$ CI 0.18-0.91) and significantly reduced by PPI (OR $0.04,95 \%$ CI 0.002-0.21), compared with that in a control group [19]. In addition, Hsiao et al. conducted a population-based, retrospective cohort study of 14,627 antiplatelet 
users (12,001 LDA users, 2,627 clopidogrel users) who had a history of hospitalization for GI complications before the initiation of antiplatelet therapy using the Taiwanese National Health Insurance database. The incidences of recurrent hospitalization for major GI complications were reported to be 0.125 per person-year in LDA users and 0.103 per person-year in LDA plus PPI users (HR 0.76, $95 \%$ CI 0.64-0.91), indicating a significant preventive effect of PPI [20].

\section{Strategies to increase adherence rate}

Education for physicians is important to raise the rate of adherence to preventive strategies for NSAID/LDA-induced GI injuries. Laine et al. [44] reported the efficacy of an intervention using a written reminder and required written response regarding preventive strategies in NSAID users. After the intervention, the rate of adherence to preventive strategies was improved from 43 to $61 \%$ in NSAID users with GI risk. Among the patients who were not provided gastroprotective agents, however, $42 \%$ of patients did not wish to take them, which indicates that education for patients is also important.

Lanas et al. conducted a prospective, observational, longitudinal study of 1,232 NSAID users with GI-related risk who were co-prescribed NSAID and gastroprotective agents for at least 15 days, and investigated adherence to these agents by telephone interviews. In terms of the reasons for nonadherence to these agents, patients most frequently cited forgetfulness [46]. Taking of NSAIDs/LDA does not necessarily cause GI symptoms, and a lack of symptoms might lead to non-adherence to gastroprotective agents due to forgetfulness, which also highlights the need for patient education.

Furthermore, Lanas et al. [45] reported that short-term treatment and adverse events were associated with poor adherence to preventive strategies. Because PPI and $\mathrm{H}_{2} \mathrm{RA}$ have been proved to be effective for preventing GI symptoms as adverse events due to NSAIDs/LDA, antisecretory therapy might help to improve the rate of adherence to NSAIDs/LDA, and might provide a better quality of life via pain control and prevention of thrombosis.

Another strategy to increase the adherence rate is to use drugs in fixed-dose combination. Several drugs including diclofenac/misoprostol, naproxen/lansoprazole, naproxen/ esomeprazole, ibuprofen/high-dose famotidine, and LDA/ esomeprazole have been developed [46-48].

\section{Changing pattern of GI events associated with NSAIDs/LDA}

A decline (from 1.5 to $0.5 \%$ ) in the rate of GI-related hospitalization from 1992 to 2000 was reported for rheumatoid arthritis patients in the USA [49]. A similar result showing a decline (from 2.1 to $1.2 \%$ ) in the rate of GI events was observed in a prospective observational study conducted in the Netherlands [50]. In addition, in a population-based study of patients hospitalized because of GI complications in 10 hospitals between 1996 and 2005 in Spain, a clear decreasing trend in upper-GI events and a significant increase in lower-GI events were demonstrated [51]. These trends over time appear to be associated with stricter adherence to preventive strategies for NSAIDinduced GI injuries.

Casado Arroyo et al. conducted a prospective observational cohort study on the incidence of GI bleeding in patients on dual antiplatelet therapy who were receiving PPI co-therapy. They reported that lower-GI bleeding occurred more frequently than upper-GI bleeding (74\% lower vs. $26 \%$ upper), and that this changing pattern of bleeding might reflect the success of gastroprotection [52].

Recently, a novel composite endpoint to evaluate the GI effects of NSAIDs through the entire GI tract, namely, clinically significant upper- and lower-GI events (CSULGIE), has been developed by a team of experts [53]. In the CONDOR trial, in which CSULGIE was used as the primary endpoint for evaluation of the GI effects of celecoxib or diclofenac plus omeprazole, 20 (0.9\%, upper GI: 8, lower GI: 12) patients receiving celecoxib and $81(3.8 \%$, upper GI: 24 , lower GI: 57) patients receiving diclofenac plus omeprazole met the criteria for the primary endpoint in a 6-month treatment period (HR 4.3, $95 \%$ CI 2.6-7.0), indicating that lower-GI events occurred more frequently than upper-GI events, and that the risk of GI events associated with celecoxib was significantly lower than that associated with diclofenac plus omeprazole [54]. In addition, clinically significant anemia (hemoglobin drop $\geq 2 \mathrm{~g} /$ $\mathrm{dL}$ and/or hematocrit drop $\geq 10 \%$ ) was reported to be the most frequent event associated with NSAID-induced lower-GI injuries [54].

\section{Conclusions and perspectives}

The efficacy of gastroprotective agents including PPIs for NSAID-induced peptic ulcers has been proved in RCT, and preventive strategies for safe prescription of NSAIDs are outlined in several guidelines. The rate of adherence to preventive strategies was reported to be low in typical practice, but has been increasing recently. Observational studies demonstrated that there is an inverse relationship between adherence to PPI therapy and the risk of upper-GI events in NSAID users. In addition, it is reported that both the risk of hospitalization due to upper-GI events and the medical cost are lower in NSAID users receiving PPI therapy than in those without PPI therapy. 
Because all NSAIDs are associated with CV-related risk, recent guidelines for the prescription of NSAIDs require patient assessments of both GI risks and CV risks when making appropriate choices of NSAIDs and gastroprotective agents. However, the assessments of $\mathrm{CV}$ risk and stratified GI risk are not fully implemented in routine clinical practice.

The efficacy of antisecretory drugs for LDA-induced peptic ulcers has also been proved in RCT. PPI therapy is recommended for the prevention of LDA-induced peptic ulcers in at-risk groups, and is reported to be associated with lower risks of upper-GI bleeding and hospitalization due to GI complications.

Furthermore, as gastroprotection spreads, the bleeding pattern due to NSAID/LDA-induced GI injuries appears to be changing from upper GI to lower GI. Further studies to identify the risk factors for NSAID/LDA-induced lower-GI injuries are required. As for the safe prescription of NSAIDs/LDA, preventive strategies for lower-GI risk are also required, in addition to $\mathrm{CV}$ risk and upper-GI risk.

In Japan, the preventive strategies upon the prescription of NSAIDs/LDA are expected to spread rapidly because the use of proton pump inhibitors for the prevention of recurrence of NSAID- or LDA-induced peptic ulcers and the use of COX-2 for the palliation of acute pain were recently approved under the national health insurance system. Further studies on the adherence to preventive strategies and the outcomes of adherence, which include both GI events and CV events, in the Japanese population are required.

Acknowledgments We thank Dr. Manabu Murakami for his helpful discussion.

Conflict of interest The authors declare that they have no conflict of interest.

Open Access This article is distributed under the terms of the Creative Commons Attribution Noncommercial License which permits any noncommercial use, distribution, and reproduction in any medium, provided the original author(s) and the source are credited.

\section{References}

1. Scarpignato C, Hunt RH. Nonsteroidal anti-inflammatory drugrelated injury to the gastrointestinal tract: clinical picture, pathogenesis, and prevention. Gastroenterol Clin North Am. 2010;39:433-64.

2. Iwamoto J, Mizokami Y, Shimokobe K, Ito M, Hirayama T, Saito $\mathrm{Y}$, et al. Clinical features of gastroduodenal ulcer in Japanese patients taking low-dose aspirin. Dig Dis Sci. 2010;55:2270-4.

3. Chan FK, Abraham NS, Scheiman JM, Laine L. Agents FIWPoGaCEoNA-iDaA-p. Management of patients on nonsteroidal anti-inflammatory drugs: a clinical practice recommendation from the First International Working Party on Gastrointestinal and Cardiovascular Effects of Nonsteroidal Anti-inflammatory Drugs and Anti-platelet Agents. Am J Gastroenterol. 2008;103: 2908-18.

4. Rostom A, Moayyedi P, Hunt R. Group CAoGC. Canadian consensus guidelines on long-term nonsteroidal anti-inflammatory drug therapy and the need for gastroprotection: benefits versus risks. Aliment Pharmacol Ther. 2009;29:481-96.

5. Lanza FL, Chan FK, Quigley EM. Gastroenterology PPCotACo. Guidelines for prevention of NSAID-related ulcer complications. Am J Gastroenterol. 2009;104:728-38.

6. Burmester G, Lanas A, Biasucci L, Hermann M, Lohmander S, Olivieri I, et al. The appropriate use of non-steroidal anti-inflammatory drugs in rheumatic disease: opinions of a multidisciplinary European expert panel. Ann Rheum Dis. 2011;70:818-22.

7. Ikaiyou gaidorain no tekiyou to hyouka ni kansuru kenkyuhan editors. EBM ni motozuku ikaiyou shinryou gaidorain dai2han. Jihou, 2007 (in Japanese).

8. The Japanese Society of Gastroenterology editors. Shoukaseikaiyou shinryou gaidorain. Nankodo, 2009 (in Japanese).

9. Smalley W, Stein CM, Arbogast PG, Eisen G, Ray WA, Griffin M. Underutilization of gastroprotective measures in patients receiving nonsteroidal antiinflammatory drugs. Arthritis Rheum. 2002;46:2195-200.

10. Abraham NS, El-Serag HB, Johnson ML, Hartman C, Richardson $\mathrm{P}$, Ray WA, et al. National adherence to evidence-based guidelines for the prescription of nonsteroidal anti-inflammatory drugs. Gastroenterology. 2005;129:1171-8.

11. Valkhoff VE, van Soest EM, Sturkenboom MC, Kuipers EJ. Time-trends in gastroprotection with nonsteroidal anti-inflammatory drugs (NSAIDs). Aliment Pharmacol Ther. 2010;31: 1218-28.

12. Lanas A, Garcia-Tell G, Armada B, Oteo-Alvaro A. Prescription patterns and appropriateness of NSAID therapy according to gastrointestinal risk and cardiovascular history in patients with diagnoses of osteoarthritis. BMC Med. 2011;9:38.

13. Goldstein JL, Howard KB, Walton SM, McLaughlin TP, Kruzikas DT. Impact of adherence to concomitant gastroprotective therapy on nonsteroidal-related gastroduodenal ulcer complications. Clin Gastroenterol Hepatol. 2006;4:1337-45.

14. van Soest EM, Sturkenboom MC, Dieleman JP, Verhamme KM, Siersema PD, Kuipers EJ. Adherence to gastroprotection and the risk of NSAID-related upper gastrointestinal ulcers and haemorrhage. Aliment Pharmacol Ther. 2007;26:265-75.

15. Abraham NS, Hartman C, Castillo D, Richardson P, Smalley W. Effectiveness of national provider prescription of PPI gastroprotection among elderly NSAID users. Am J Gastroenterol. 2008;103:323-32.

16. Tsumura H, Fujita T, Tamura I, Morita Y, Yoshida M, Toyonaga $\mathrm{T}$, et al. Association between adherence to evidence-based guidelines for the prescription of non-steroidal anti-inflammatory drugs and the incidence of gastric mucosal lesions in Japanese patients. J Gastroenterol. 2010;45:944-51.

17. Abraham NS, Hartman C, Hasche J. Reduced hospitalization cost for upper gastrointestinal events that occur among elderly veterans who are gastroprotected. Clin Gastroenterol Hepatol 2010;8:350-6; quiz e45.

18. van Soest EM, Valkhoff VE, Mazzaglia G, Schade R, Molokhia M, Goldstein JL, et al. Suboptimal gastroprotective coverage of NSAID use and the risk of upper gastrointestinal bleeding and ulcers: an observational study using three European databases. Gut. 2011;60:1650-9.

19. Ng FH, Lam KF, Wong SY, Chang CM, Lau YK, Yuen WC, et al. Upper gastrointestinal bleeding in patients with aspirin and clopidogrel co-therapy. Digestion. 2008;77:173-7.

20. Hsiao FY, Tsai YW, Huang WF, Wen YW, Chen PF, Chang PY, et al. A comparison of aspirin and clopidogrel with or without 
proton pump inhibitors for the secondary prevention of cardiovascular events in patients at high risk for gastrointestinal bleeding. Clin Ther. 2009;31:2038-47.

21. Sugano K, Kontani T, Katsuo S, Takei Y, Sakaki N, Ashida K, et al. Lansoprazole for secondary prevention of gastric or duodenal ulcers associated with long-term non-steroidal antiinflammatory drug (NSAID) therapy: results of a prospective, multicenter, double-blind, randomized, double-dummy, activecontrolled trial. J Gastroenterol. 2012;47:540-52.

22. Sugano K, Kinoshita Y, Miwa H, Takeuchi T, Group ENPS. Randomised clinical trial: esomeprazole for the prevention of nonsteroidal anti-inflammatory drug-related peptic ulcers in Japanese patients. Aliment Pharmacol Ther. 2012;36:115-25.

23. Scheiman JM, Yeomans ND, Talley NJ, Vakil N, Chan FK, Tulassay Z, et al. Prevention of ulcers by esomeprazole in at-risk patients using non-selective NSAIDs and COX-2 inhibitors. Am J Gastroenterol. 2006;101:701-10.

24. Chan FK, Chung SC, Suen BY, Lee YT, Leung WK, Leung VK, et al. Preventing recurrent upper gastrointestinal bleeding in patients with Helicobacter pylori infection who are taking lowdose aspirin or naproxen. N Engl J Med. 2001;344:967-73.

25. Lai KC, Lam SK, Chu KM, Hui WM, Kwok KF, Wong BC, et al. Lansoprazole reduces ulcer relapse after eradication of Helicobacter pylori in nonsteroidal anti-inflammatory drug users-a randomized trial. Aliment Pharmacol Ther. 2003;18:829-36.

26. Graham DY, Agrawal NM, Campbell DR, Haber MM, Collis C, Lukasik NL, et al. Ulcer prevention in long-term users of nonsteroidal anti-inflammatory drugs: results of a double-blind, randomized, multicenter, active- and placebo-controlled study of misoprostol vs lansoprazole. Arch Intern Med. 2002;162:169-75.

27. Chan FK, Hung LC, Suen BY, Wu JC, Lee KC, Leung VK, et al. Celecoxib versus diclofenac and omeprazole in reducing the risk of recurrent ulcer bleeding in patients with arthritis. N Engl J Med. 2002;347:2104-10.

28. Lai KC, Chu KM, Hui WM, Wong BC, Hu WH, Wong WM, et al. Celecoxib compared with lansoprazole and naproxen to prevent gastrointestinal ulcer complications. Am J Med. 2005;118:1271-8.

29. Chan FK, Hung LC, Suen BY, Wong VW, Hui AJ, Wu JC, et al. Celecoxib versus diclofenac plus omeprazole in high-risk arthritis patients: results of a randomized double-blind trial. Gastroenterology. 2004;127:1038-43.

30. Chan FK, Wong VW, Suen BY, Wu JC, Ching JY, Hung LC, et al. Combination of a cyclo-oxygenase-2 inhibitor and a protonpump inhibitor for prevention of recurrent ulcer bleeding in patients at very high risk: a double-blind, randomised trial. Lancet. 2007;369:1621-6.

31. Sugano K, Matsumoto Y, Itabashi T, Abe S, Sakaki N, Ashida K, et al. Lansoprazole for secondary prevention of gastric or duodenal ulcers associated with long-term low-dose aspirin therapy: results of a prospective, multicenter, double-blind, randomized, double-dummy, active-controlled trial. J Gastroenterol. 2011;46: 724-35.

32. AstraZeneca, Daiichi Sankyo Co., Ltd. http://www.info.pmda.go. jp/downfiles/ph/PDF/670227_2329029M1027_1_04.pdf (in Japanese).

33. Sanuki T, Fujita T, Kutsumi H, Hayakumo T, Yoshida SI, Inokuchi $\mathrm{H}$, et al. Rabeprazole reduces the recurrence risk of peptic ulcers associated with low-dose aspirin in patients with cardiovascular or cerebrovascular disease: a prospective randomized active-controlled trial. J Gastroenterol. 2012;47:1186-97.

34. Yeomans N, Lanas A, Labenz J, van Zanten SV, van Rensburg C, Rácz I, et al. Efficacy of esomeprazole ( $20 \mathrm{mg}$ once daily) for reducing the risk of gastroduodenal ulcers associated with continuous use of low-dose aspirin. Am J Gastroenterol. 2008;103:2465-73.

35. Scheiman JM, Devereaux PJ, Herlitz J, Katelaris PH, Lanas A, Veldhuyzen van Zanten S, et al. Prevention of peptic ulcers with esomeprazole in patients at risk of ulcer development treated with low-dose acetylsalicylic acid: a randomised, controlled trial (OBERON). Heart. 2011;97:797-802.

36. Taha AS, McCloskey C, Prasad R, Bezlyak V. Famotidine for the prevention of peptic ulcers and oesophagitis in patients taking low-dose aspirin (FAMOUS): a phase III, randomised, doubleblind, placebo-controlled trial. Lancet. 2009;374:119-25.

37. Lai KC, Lam SK, Chu KM, Wong BC, Hui WM, Hu WH, et al. Lansoprazole for the prevention of recurrences of ulcer complications from long-term low-dose aspirin use. N Engl J Med. 2002;346:2033-8.

38. Ng FH, Wong SY, Lam KF, Chu WM, Chan P, Ling YH, et al. Famotidine is inferior to pantoprazole in preventing recurrence of aspirin-related peptic ulcers or erosions. Gastroenterology. 2010;138:82-8.

39. Ng FH, Tunggal P, Chu WM, Lam KF, Li A, Chan K, et al. Esomeprazole compared with famotidine in the prevention of upper gastrointestinal bleeding in patients with acute coronary syndrome or myocardial infarction. Am J Gastroenterol. 2012;107:389-96.

40. Bhatt DL, Cryer BL, Contant CF, Cohen M, Lanas A, Schnitzer $\mathrm{TJ}$, et al. Clopidogrel with or without omeprazole in coronary artery disease. N Engl J Med. 2010;363:1909-17.

41. McGettigan P, Henry D. Cardiovascular risk with non-steroidal anti-inflammatory drugs: systematic review of population-based controlled observational studies. PLoS Med. 2011;8:e1001098.

42. Bhatt DL, Scheiman J, Abraham NS, Antman EM, Chan FK, Furberg CD, et al. ACCF/ACG/AHA 2008 expert consensus document on reducing the gastrointestinal risks of antiplatelet therapy and NSAID use: a report of the American College of Cardiology Foundation Task Force on Clinical Expert Consensus Documents. J Am Coll Cardiol. 2008;52:1502-17.

43. Lanas A, Scheiman J. Low-dose aspirin and upper gastrointestinal damage: epidemiology, prevention and treatment. Curr Med Res Opin. 2007;23:163-73.

44. Laine L, Connors L, Griffin MR, Curtis SP, Kaur A, Cannon CP. Prescription rates of protective co-therapy for NSAID users at high GI risk and results of attempts to improve adherence to guidelines. Aliment Pharmacol Ther. 2009;30:767-74.

45. Lanas A, Polo-Tomás M, Roncales P, Gonzalez MA, Zapardiel J. Prescription of and adherence to non-steroidal anti-inflammatory drugs and gastroprotective agents in at-risk gastrointestinal patients. Am J Gastroenterol. 2012;107:707-14.

46. Schiff M, Peura D. HZT-501 (DUEXIS(®); ibuprofen $800 \mathrm{mg} /$ famotidine $26.6 \mathrm{mg}$ ) gastrointestinal protection in the treatment of the signs and symptoms of rheumatoid arthritis and osteoarthritis. Expert Rev. Gastroenterol Hepatol. 2012;6:25-35.

47. Dhillon S. Naproxen/esomeprazole fixed-dose combination: for the treatment of arthritic symptoms and to reduce the risk of gastric ulcers. Drugs Aging. 2011;28:237-48.

48. Burness CB, Scott LJ. Acetylsalicylic acid/esomeprazole fixeddose combination. Drugs Aging. 2012;29:233-42.

49. Fries JF, Murtagh KN, Bennett M, Zatarain E, Lingala B, Bruce B. The rise and decline of nonsteroidal antiinflammatory drugassociated gastropathy in rheumatoid arthritis. Arthritis Rheum. 2004;50:2433-40.

50. Steen KS, Nurmohamed MT, Visman I, Heijerman M, Boers M, Dijkmans BA, et al. Decreasing incidence of symptomatic gastrointestinal ulcers and ulcer complications in patients with rheumatoid arthritis. Ann Rheum Dis. 2008;67:256-9.

51. Lanas A, García-Rodríguez LA, Polo-Tomás M, Ponce M, Alonso-Abreu I, Perez-Aisa MA, et al. Time trends and impact of upper and lower gastrointestinal bleeding and perforation in clinical practice. Am J Gastroenterol. 2009;104:1633-41.

52. Casado Arroyo R, Polo-Tomas M, Roncalés MP, Scheiman J, Lanas A. Lower GI bleeding is more common than upper among 
patients on dual antiplatelet therapy: long-term follow-up of a cohort of patients commonly using PPI co-therapy. Heart. 2012;98:718-23.

53. Chan FK, Cryer B, Goldstein JL, Lanas A, Peura DA, Scheiman JM, et al. A novel composite endpoint to evaluate the gastrointestinal (GI) effects of nonsteroidal antiinflammatory drugs through the entire GI tract. J Rheumatol. 2010;37:167-74.
54. Chan FK, Lanas A, Scheiman J, Berger MF, Nguyen H, Goldstein JL. Celecoxib versus omeprazole and diclofenac in patients with osteoarthritis and rheumatoid arthritis (CONDOR): a randomised trial. Lancet. 2010;376:173-9. 